\title{
A Collaborative Education Mechanism for College Students' Physical and Mental Health Education and Safety Education Under Complex Background
}

\author{
https://doi.org/10.3991/ijet.v17i04.29581 \\ Song Xiaoning ${ }^{1(\varpi)}$, Lin Nailei ${ }^{2}$ \\ ${ }^{1}$ Student Work Department of the Party committee, Tangshan Polytechnic College, Tangshan, \\ China \\ ${ }^{2}$ School of Marxism, Tangshan Polytechnic College, Tangshan, China \\ songxiaoning@tsgzy.edu.cn
}

\begin{abstract}
The current system for college students' physical and mental health education and safety education in China is incomplete, however, a sound system is of important significance for exploring new ideas and ways for college students' physical and mental health education and safety education, improving the health level of college students, and implementing the requirements of "healthy China initiative" for higher education. Until now, few studies have concerned about the construction of a collaborative education mechanism for college students' physical and mental health and safety education under complex background, therefore, this paper attempts to fill in this research gap. In the beginning of this paper, qualitative and quantitative methods were combined to build a content system for college students' physical and mental health education and safety education under complex background; then, a coordination evaluation model for the said matter was constructed, and principles for dividing the coupling coordination types of the collaborative education system were elaborated. After that, the grey prediction model was employed to predict and analyze the development status of collaborative education of college students' physical and mental health education and safety education, thereby realizing rational judgement of the development trend of collaborative education. At last, test results compared the actual value and grey prediction value of the coordination degree of collaborative education, and proved the effectiveness of the constructed model.
\end{abstract}

Keywords-physical health, mental health, safety education, collaborative education

\section{$1 \quad$ Introduction}

Unhealthy lifestyle and bad living habits have become great threats to contemporary college students [1-5]. Statistics suggest that non communicable diseases exhibit younger age trend, the infection rate of major communicable diseases is on the rise year by year, and extreme injury events caused by mental health problems occur more 
frequently [6-11]. Under such severe and complex background, the education system for college students' physical and mental health education and safety education in China is still incomplete [12-17], however, constructing a content system and a coordination evaluation model for the said matter is of important significance for exploring new ideas and ways for college students' physical and mental health education and safety education, improving the health level of college students, and implementing the requirements of "healthy China initiative" for higher education.

Miao et al. [18] developed course materials for health and safety technology class, including complete study and review modules, such as classroom demonstration, laboratory activities, homework and quiz, and experiment verification, etc. For graduates just being employed, their work practice related to machine protection had been significantly improved, their attitudes toward safety rules and their evaluation of the safety atmosphere of workplace make them more adaptable to deal with the variability of work practice. For industries in which projects are the main work mode, they have to face risks in health, safety, and environment at the same time, for this matter, Huang and Gao [19] discussed the educational content of health, safety, and environment in project management (PM) teaching in undergraduate education of Norwegian construction engineers, and proved that adding such educational content can effectively improve future engineers' ability in implementing health and safety measures in the construction industry. While the problem of college students' physical quality has attracted the attention of the society, Chinese government has formulated a set of physical quality mechanism according to national sports health standards and given strict evaluations on the health status of contemporary college students. Miao et al. [18] used SPSS 20.0 to analyze the evaluation methods of contemporary college students' physical health, and established an overall framework of contemporary college students' health reference standards; by referring to the national student health standards, a set of health-based physical quality standards had been formed, which can be used for the prediction of future adult physical quality reference standards in advance. With the advancement of human civilization, people are entering a society of risks, and how to educate students while ensuring their safety in such a risky social environment is an important task for Chinese colleges and universities, in view of this problem, Yang [20] analyzed the connotation of college students' safety education from the perspective of risk sociology, summarized the types of college students' safety risks in China, and proposed a few strategies for implementing college students' safety education from two aspects of safety awareness education and technology education.

Existing studies mostly focus on aspects such as the evaluation of college students' physical and mental health quality or their requirements for safety education, few have concerned about the construction of a collaborative mechanism for physical and mental health and safety education under complex background. How to formulate targeted content for comprehensive collaborative education of college students' physical and mental health education, and how to establish a scientific, reasonable, and feasible collaborative education mechanism, are difficult research points for field scholars and educators. For this reason, this paper attempts to explore the collaborative education mechanism of college students' physical and mental health and safety 
education under complex background. The second chapter combined qualitative and quantitative methods to build a content system for college students' physical and mental health education and safety education under complex background; the third chapter constructed a model to evaluate the coordination degree of the collaborative education system for the said matter, and elaborated on the principles for dividing the coupling coordination types of the collaborative education system. The fourth chapter employed the grey prediction model to predict and analyze the development status of collaborative education of college students' physical and mental health education and safety education, and gave rational judgement of the development trend of collaborative education. In the last chapter, test results compared the actual value and grey prediction value of the coordination degree of collaborative education, and proved the effectiveness of the constructed model.

\section{Construction of Evaluation Index System (EIS) for collaborative education}

Figure 1 gives a diagram of the collaborative education mechanism of college students' physical and mental health education and safety education, and it shows the coordination and coupling relationship between the two kinds of education. Based on existing literatures, previous works, and the principles of scientificity, systematicness and applicability, this paper referred to the coordination and coupling relationship between the two education systems and combined qualitative and quantitative methods to construct a content system for college students' physical and mental health education and safety education under complex background. The constructed content system contains three levels: the first-level content items include 4 aspects of physical quality improvement $C E_{1}$, mental quality improvement $C E_{2}$, life and safety education $C E_{3}$, and popularization of relevant scientific knowledge $C E_{4}$.

Specifically, physical quality improvement includes 4 aspects of healthy lifestyle, chronic disease prevention, infectious disease prevention, and gender health; mental quality improvement includes 2 aspects of basic mental health knowledge, and mental health education; life and safety education includes 2 aspects of life frustration education, and first aid and risk avoidance education; popularization of relevant scientific knowledge includes 2 aspects of common health care methods, and health and environment. 


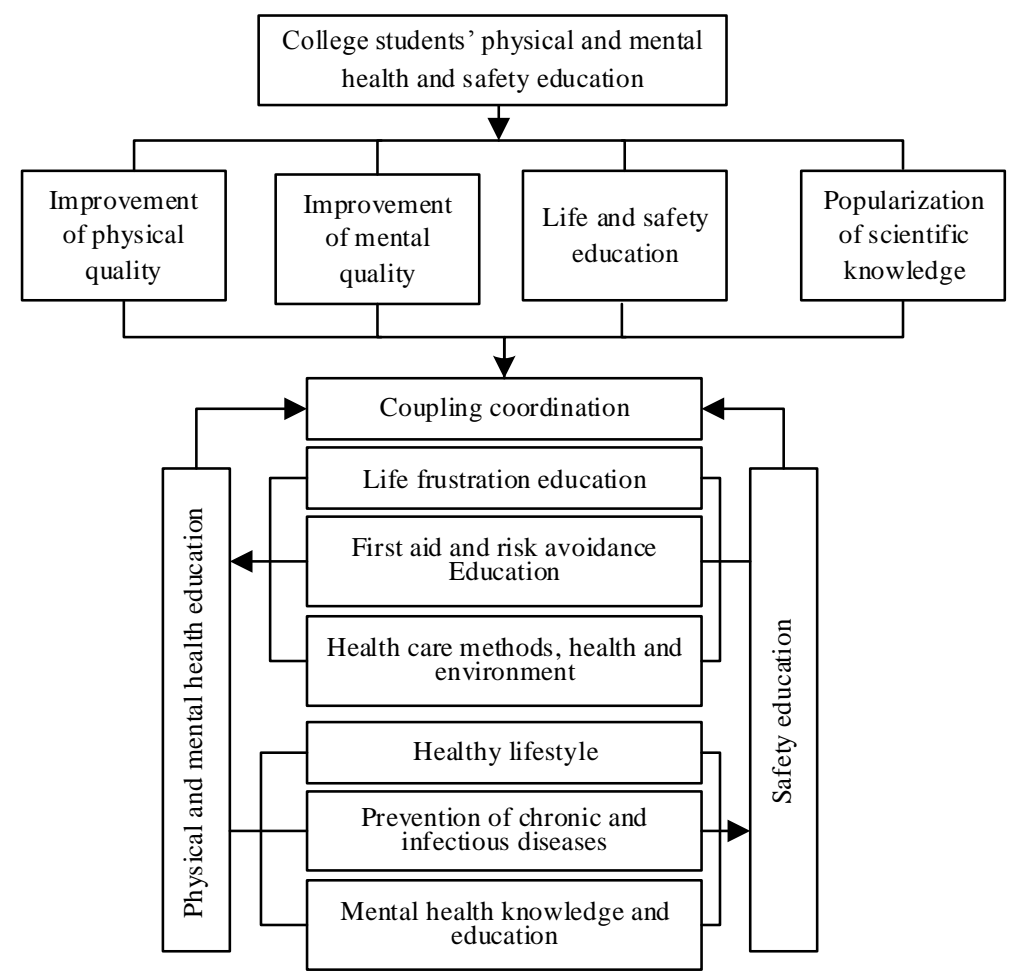

Fig. 1. A diagram of the collaborative education mechanism of college students' physical and mental health and safety education

More specifically, healthy lifestyle includes 8 aspects of sports \& exercise, sleep and rest, balanced diet, personal hygiene, drug use, Internet addiction, tobacco addiction, and alcohol addiction; chronic disease prevention includes 3 aspects of common symptoms, risk factors, and preventive measures; infectious disease prevention includes 3 aspects of infectious source, transmission process, personal protection and vaccination; gender health includes 3 aspects of AIDS prevention, sexual behavior and sexual psychological health, contraceptive methods and the harm of induced abortion. Basic mental health knowledge includes 3 aspects of mental health standards, abnormal psychological performance, and psychological counseling methods. Mental health education includes 3 aspects of emotion management, stress management, and cultivation of correct values. Life frustration education includes 3 aspects of life meaning education, death education, and life-cherishing education. First aid and risk avoidance education includes 2 aspects of first aid knowledge and skills, and risk avoidance knowledge and skills. Common health care methods include 3 aspects of diet health care, exercise health care, and negative emotion elimination. Health and environment include 3 aspects of living environment and health, public environment and health, and natural environment and health. 
Weight can reflect the relative importance of each content item in the proposed content system. In essence, the weight value is the percentage of a content item in the whole content system, which is not only the result of the overall subjective and objective measurement of the content, but also the objective reflection of the attribute of the content item, moreover, it is also the basis of this research. For these content items in the proposed system, their importance degrees are different, and the reasonable setting of the weight values of content items in each level can directly affect the scientificity of the content system. In this paper, the entropy weight method was adopted to assign weight values to the proposed content system.

Before calculating the weight values, all content items in the content system were normalized to ensure that all of their values were within the value range of $[0,1]$. Assuming: $a_{j}$ represents the original value of the $j$-th content item; $a^{\max }{ }_{j}$ and $a^{\min }{ }_{j}$ respectively represent the maximum and minimum values of the $j$-th content item. This paper adopted the linear dimensionless extreme value method, and Formula 1 gives the calculation formula of forward dimensionless processing:

$$
A_{j}=\left(a_{j}-a_{j}^{\min }\right) /\left(a_{j}^{\max }-a_{j}^{\min }\right)
$$

Formula 2 gives the calculation formula of reverse dimensionless processing:

$$
A_{j}=\left(a_{j}^{\max }-a_{j}\right) /\left(a_{j}^{\max }-a_{j}^{\min }\right)
$$

Assuming: $a_{i j}$ represents the $i$-th value under the $j$-th content item, then, a content item data matrix can be constructed as Formula 3:

$$
E=\left[\begin{array}{cccc}
a_{11} & a_{12} & \cdots & a_{1 j} \\
a_{21} & a_{22} & \cdots & a_{2 j} \\
\vdots & \vdots & \ddots & \vdots \\
a_{i 1} & a_{i 2} & \cdots & a_{i j}
\end{array}\right]
$$

Assuming: $U_{i j}$ represents the contribution degree of the $i$-th value to the $j$-th content item, $n$ represents the number of values contained in a single content item, then, the proportion of the utility value of a content item can be calculated using Formula 4:

$$
U_{i j}=\frac{a_{i j}}{\sum_{i=1}^{n} a_{i j}}
$$

Assuming: $S_{j}$ represents the information entropy, namely the total contribution of value $a_{j}$ to each content item, then its calculation formula is given in Formula 5:

$$
S_{j}=-L \sum^{n} U_{i j} \ln \left(U_{i j}\right)
$$

In above formula, $L$ is a constant, which satisfies $L=1 / \ln (n)$. Assuming: $\varepsilon_{j}$ represents the consistency of the contribution degree of each value under the $j$-th content 
item, then, the redundancy rate of the $j$-th content item can be calculated by Formula 6 :

$$
\varepsilon_{j}=1-S_{j}
$$

The weight of the $j$-th content item can be obtained through Formula 7:

$$
\omega_{j}=\frac{\varepsilon_{j}}{\sum_{j=1}^{m} \varepsilon_{j}}
$$

\section{Construction of the coupling coordination model for collaborative education}

The interaction between two systems is defined as the coupling phenomenon. During the process of collaborative education of college students' physical and mental health education and safety education under complex background, the physical and mental health education, and the safety education, are two independent and interrelated education systems, and there is a coordinated coupling relationship between them. The two education systems act in coordination, showing a benign, interactive, and mutually-promotive relationship.

Before constructing the coordination evaluation model, at first, this paper chose to use the linear weighted sum method to measure the evaluation indexes of the two education systems (physical and mental health education, and the safety education) from both horizontal and vertical angles, and the measured evaluation indexes were adopted as measures for the level of the two systems. Assuming: $\omega_{j}$ represents the weight of the $j$-th content item, $a_{i j}$ represents the $i$-th value corresponding to the $j$-th content item after normalization processing. Formula 8 gives the evaluation formula of the linear weighted sum:

$$
g_{(a)}=\sum_{j=1}^{n} \omega_{j} a_{i j}
$$

Based on above formula, the evaluation model of proposed content system could be constructed further:

$$
\begin{aligned}
& g_{(V)}=\sum_{j=1}^{n} e_{j} V_{i j} \\
& h_{(S)}=\sum_{j=1}^{m} r_{j} S_{i j}
\end{aligned}
$$


Assuming: $e_{j}$ and $r_{j}$ represent the weight values of the $j$-th content item respectively belonging to the content system of the two education systems, and $V_{i j}$ and $S_{i j}$ represent the data of each content item after normalization:

Assuming: $g_{(V)}$ and $h_{(S)}$ are the evaluation indexes of the two systems, after constructing the evaluation model of the two systems, Formula 11 gives the expression of the coupling coordination evaluation model:

$$
Q S=\left\{g_{(V)} \cdot h_{(S)} /\left[g_{(V)}+h_{(S)}\right]^{2}\right\}^{1 / 2}
$$

However, due to the particularity of the content system, coupling coordination is unable to reflect the independent functions of the two systems, thus it can cause errors, and to eliminate such errors and truthfully reflect the scientificity of the content system, here it's assumed that: $Q S$ represents the coupling degree of the two education systems (physical and mental health education and safety education), $C W$ represents the comprehensive coordination index of the collaborative education of the two education systems; $\delta$ and $\gamma$ respectively represent the contribution shares of the two education systems, then, the coupling coordination models shown as Formulas 12 and 13 can be introduced:

$$
\begin{gathered}
Q W=\sqrt{Q S \times C W} \\
C W=\delta \cdot g_{(V)}+\gamma \cdot h_{(S)}
\end{gathered}
$$

To intuitively reflect the comprehensive coordination of the two education systems under complex background, referring to the research results of other scholars, the comprehensive coordination degree of the two education systems was divided into several consecutive intervals according to the uniform distribution function method, then, an evaluation table of corresponding coupling coordination types could be obtained. Table 1 lists the principles for the classification of coupling coordination types of the two education systems.

\begin{tabular}{|c|c|c|c|c|c|}
\hline $\begin{array}{l}\text { Value range of } \\
\text { Coordination }\end{array}$ & $(0,0.1]$ & $(0.11,0.2]$ & $(0.2,0.3]$ & $(0.3,0.4]$ & $(0.4,0.5]$ \\
\hline $\begin{array}{c}\text { Degree of } \\
\text { coordination }\end{array}$ & $\begin{array}{c}\text { Moderately } \\
\text { uncoordinated }\end{array}$ & $\begin{array}{c}\text { Extremely } \\
\text { uncoordinated }\end{array}$ & $\begin{array}{l}\text { Nearly uncoor- } \\
\text { dinated }\end{array}$ & $\begin{array}{l}\text { Slightly uncoor- } \\
\text { dinated }\end{array}$ & $\begin{array}{l}\text { Severely unco- } \\
\text { ordinated }\end{array}$ \\
\hline $\begin{array}{l}\text { Value range of } \\
\text { Coordination }\end{array}$ & $(0.5,0.6]$ & $(0.6,0.7]$ & $(0.7,0.8]$ & $(0.8,0.9]$ & $(0.9,1.0]$ \\
\hline $\begin{array}{c}\text { Degree of } \\
\text { coordination }\end{array}$ & $\begin{array}{c}\text { Well } \\
\text { coordinated }\end{array}$ & $\begin{array}{c}\text { Barely } \\
\text { coordinated }\end{array}$ & $\begin{array}{c}\text { Very well coor- } \\
\text { dinated }\end{array}$ & $\begin{array}{l}\text { Moderately } \\
\text { coordinated }\end{array}$ & $\begin{array}{c}\text { Primely } \\
\text { coordinated }\end{array}$ \\
\hline
\end{tabular}

Table 1. Principles for the classification of coupling coordination types of the two education systems 


\section{Construction of coupling coordination prediction model of collaborative education based on GM $(1,1)$}

Studying the coupling coordination of collaborative education of the two education systems can help us make judgement on the changes in the coupling coordination relationship during the process of collaborative education, however, it couldn't judge the rationality of this coordinated development trend, that is, it is impossible to judge whether the two education systems are beneficial to the sustainable and coordinated development of college students' physical and mental health education and safety education, and it is more difficult to timely regulate their development mode from perspectives of policy and direction. Therefore, this paper adopted the grey prediction model to predict and analyze the development status of the collaborative education of college students' physical and mental health education and safety education.

Assuming: the number sequence of all content items in the content system $A^{(0)}=\left\{A^{(0)}{ }_{1}, A^{(0)}{ }_{2}, \ldots \ldots, A^{(0)}{ }_{m}\right\}$ is an original nonnegative sequence, then it is accumulated and the obtained one-time accumulated sequence can be expressed as $A^{(1)}=\left\{A^{(1)}{ }_{1}, A^{(1)}{ }_{2}, \ldots \ldots, A^{(1)}{ }_{m}\right\}$, and it satisfies $A^{(1)}{ }_{l}=\sum_{i=1}^{l} A^{(0)}{ }_{i}, l=1,2, \ldots, m$.

Formula 14 gives the expression of the grey derivative of $A^{(1)}$ :

$$
\varepsilon(l)=A^{(0)}(l)=A^{(1)}(l)-A^{(1)}(l-1), l=2,3, \ldots, m
$$

Assuming: $C^{(1)}$ represents the sequence generated by the neighbor values of $A^{(1)}$, then there is:

$$
C^{(1)}=\delta A^{(1)}(l)+(1-\delta) A^{(1)}(l-1), l=2,3, \ldots, m
$$

Based on the original sequence $A^{(0)}$ and the sequence generated by the neighbor values $C^{(1)}$, the GM $(1,1)$ grey differential equations could be constructed as follows:

$$
\left\{\begin{array}{l}
A_{2}^{(0)}+e C_{2}^{(1)}=r \\
A_{3}^{(0)}+e C_{3}^{(1)}=r \\
\cdots \\
A_{m}^{(0)}+e C_{m}^{(1)}=r
\end{array}\right.
$$

Let:

$$
v=\left[\begin{array}{l}
e \\
r
\end{array}\right]
$$




$$
\begin{gathered}
B=\left[\begin{array}{l}
A_{2}^{(0)} \\
A_{3}^{(0)} \\
\vdots \\
A_{m}^{(0)}
\end{array}\right] \\
R=\left[\begin{array}{ll}
-C_{2}^{(1)} & 1 \\
-C_{3}^{(1)} & 1 \\
\vdots & \vdots \\
-C_{m}^{(1)} & 1
\end{array}\right]
\end{gathered}
$$

Based on the least square method, the values of parameters $e$ and $r$ can be calculated:

$$
\dot{v}=\left[\begin{array}{c}
\dot{e} \\
\dot{r}
\end{array}\right]=\left(R^{T} R\right)^{-1} R^{T} B
$$

Assuming: $\varphi$ represents time, then, a whitening model could be constructed as shown in Formula 21:

$$
\frac{d A_{\phi}^{(1)}}{d \phi}+e A_{\phi}^{(1)}=r
$$

Through the derivation of the above formula, the time response formula shown as Formula 22 can be obtained:

$$
A_{\phi+1}^{(1)}=\left(A_{1}^{(0)}-\frac{r}{e}\right) p^{-e \phi}+\frac{r}{e}
$$

By reducing Formula 22, the prediction formula shown as Formula 23 can be obtained:

$$
A_{\phi+1}^{(0)}=A_{\phi+1}^{(1)}-A_{\phi}^{(1)}
$$

Finally, this paper tested the prediction accuracy of the grey prediction model based on the posterior error test method. The verification steps are described below. First, the mean value was calculated using Formula 24:

$$
\bar{A}=\frac{1}{m} \sum_{i=1}^{m} A_{i}^{(0)}
$$

Then, variance $F C_{1}$ was calculated based on Formula 25: 


$$
F C_{1}=\sqrt{\frac{1}{m} \sum_{i=1}^{m}\left(A_{i}^{(0)}-\bar{A}\right)^{2}}
$$

Formula 26 gives the calculation formula of residual $R C_{\mathrm{i}}$ :

$$
R C_{i}=A_{i}^{(0)}-A_{i}^{(1)}
$$

After that, the mean of residual could be calculated using Formula 27:

$$
\overline{R C}=\frac{1}{m-1} \sum_{i=2}^{m} R C_{i}
$$

The variance of the residual $F C_{2}$ can be calculated by Formula 28:

$$
F C_{2}=\sqrt{\frac{1}{m-1} \sum_{i=2}^{m}\left(R C_{i}-\overline{R C}\right)^{2}}
$$

The posterior error ratio $\eta$ was calculated by Formula 29:

$$
\eta=\frac{F C_{2}}{F C_{1}}
$$

Finally, the small error probability $W L$ was obtained through the following formula:

$$
W L=W L\left\{0.6745 F C_{1}>\left|R C_{i}-\overline{R C}\right|\right\}
$$

Table 2 gives the accuracy comparison table of the constructed prediction model.

Table 2. Comparison of model accuracy

\begin{tabular}{|l|c|c|c|c|}
\hline \multicolumn{1}{|c|}{ Level of accuracy } & Unqualified & Barely qualified & Qualified & Good \\
\hline$W L$ & {$[0,0.7)$} & {$[0.7,0.85)$} & {$[0.85,0.95)$} & {$[0.95,1]$} \\
\hline$H$ & {$[0.7,0.1]$} & $(0.5,0.7]$ & {$[0.04,0.5)$} & $(0,0.4]$ \\
\hline
\end{tabular}

\section{Analysis of experimental results}

This paper employed the entropy weight method to assign weight for the content system. Taking the 4 first-level content items as examples, the calculation results of the adopted method are displayed. Table 3 gives the judgment matrix based on the entropy weight method.

According to the calculation method described in the previous section, the evaluation indexes of college students' physical and mental health education and safety education of the studied colleges from 2008 to 2019 were calculated, and the results are 
shown in Table 4. Figure 2 shows the changes of evaluation indexes of the two education systems from 2008 to 2020 . As can be seen from the figure, after applying the collaborative education mechanism, the evaluation indexes of the two education systems showed an upward trend year by year.

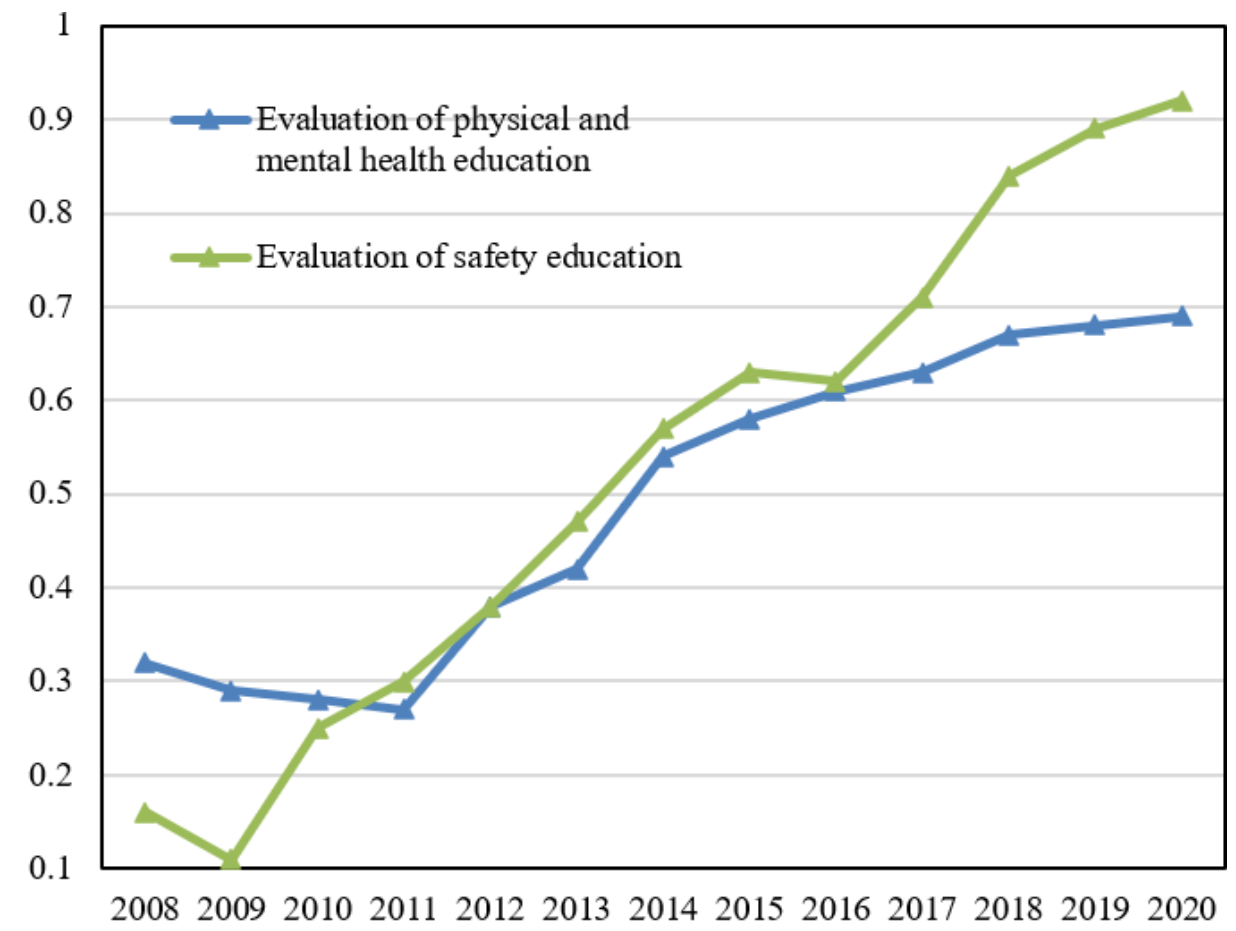

Fig. 2. Changes of evaluation indexes of the two education systems from 2008 to 2019

Table 3. The judgment matrix

\begin{tabular}{|l|c|c|c|c|}
\hline \multicolumn{1}{|c|}{ Index item } & $\boldsymbol{C E}_{\mathbf{1}}$ & $\boldsymbol{C E}_{\mathbf{2}}$ & $\boldsymbol{C E}_{\mathbf{3}}$ & $\boldsymbol{C E}_{\mathbf{4}}$ \\
\hline$C E_{1}$ & 2 & 0.985 & 0.924 & 0.864 \\
\hline$C E_{2}$ & 1.124 & 3 & 0.984 & 0.927 \\
\hline$C E_{3}$ & 1.082 & 1.162 & 2 & 0.982 \\
\hline$C E_{4}$ & 1.254 & 1.164 & 0.964 & 3 \\
\hline Eigenvector & 1.168 & 1.127 & 0.894 & 0.937 \\
\hline Weight & $26.72 \%$ & $25.16 \%$ & $24.38 \%$ & $23.48 \%$ \\
\hline Mean & 4.83 & 4.92 & 4.58 & 4.68 \\
\hline Maximum eigenvalue & \multicolumn{5}{|c|}{0.125} \\
\hline$C I$ value & \multicolumn{5}{|c|}{0.002} \\
\hline
\end{tabular}


Paper-A Collaborative Education Mechanism for College Students' Physical and Mental Health...

Table 4. Evaluation indexes of the two education systems from 2008 to 2019

\begin{tabular}{|l|c|c|c|c|c|c|}
\hline Year & $\mathbf{2 0 0 8}$ & $\mathbf{2 0 0 9}$ & $\mathbf{2 0 1 0}$ & $\mathbf{2 0 1 1}$ & $\mathbf{2 0 1 2}$ & $\mathbf{2 0 1 3}$ \\
\hline$g_{(V)}$ & 0.1254 & 0.1352 & 0.2543 & 0.3128 & 0.3246 & 0.4328 \\
\hline$h_{(S)}$ & 0.3284 & 0.2746 & 0.2916 & 0.2641 & 0.3162 & 0.3341 \\
\hline Year & $\mathbf{2 0 1 4}$ & $\mathbf{2 0 1 5}$ & $\mathbf{2 0 1 6}$ & $\mathbf{2 0 1 7}$ & $\mathbf{2 0 1 8}$ & $\mathbf{2 0 1 9}$ \\
\hline$g_{(V)}$ & 0.4675 & 0.5216 & 0.6253 & 0.7846 & 0.8246 & 0.8354 \\
\hline$h_{(S)}$ & 0.4287 & 0.5316 & 0.5827 & 0.6728 & 0.6928 & 0.6996 \\
\hline
\end{tabular}

In view of the development status of the coupling coordination relationship between the two education systems in the 4 colleges from 2018 to 2020, this paper constructed a grey prediction model and used it to predict the development status of the coupling coordination of the two education systems in the 4 different colleges from 2021 to 2023, Table 4 gives the specific actual values and predicted values. Figure 3 shows the fitting diagram of the actual and predicted development trend from 2010 to 2025.

According to Table 5, the variance ratios of grey prediction values of College B and College D are 0.2628 and 0.2642 respectively, and their small error probabilities are 1 and 0.9879 respectively. It can be seen that the grey prediction accuracy of these two colleges is good, and it is of high reference value for the predicted values of college students' physical and mental health education and safety education in complex environment from 2020 to 2025 . The variance ratios of grey prediction values of College A and College B are 0.3842 and 0.3957 respectively, and their small error probabilities are 0.8874 and 0.8915 respectively. The grey prediction accuracy is qualified, and it is of certain reference value for the predicted values of college students' physical and mental health education and safety education in complex environment from 2020 to 2025 .

Table 5. Actual and predicted situation of coupling coordination of collaborative education from 2018 to 2023

\begin{tabular}{|l|c|c|c|c|c|c|c|c|c|c|}
\hline \multicolumn{2}{|c|}{ Year } & $\mathbf{2 0 1 8}$ & $\mathbf{2 0 1 9}$ & $\mathbf{2 0 2 0}$ & $\mathbf{2 0 2 1}$ & $\mathbf{2 0 2 2}$ & $\mathbf{2 0 2 3}$ & $\begin{array}{l}\text { Relative } \\
\text { residual }\end{array}$ & $\begin{array}{c}\text { Variance } \\
\text { ratio }\end{array}$ & $\begin{array}{c}\text { Small error } \\
\text { probability }\end{array}$ \\
\hline $\begin{array}{l}\text { College } \\
\text { A }\end{array}$ & Actual value & 0.631 & 0.394 & 0.618 & & & & & & \\
\cline { 2 - 11 } & Predicted value & 0.622 & 0.637 & 0.691 & 0.712 & 0.724 & 0.736 & 0.016 & 0.3842 & 0.8874 \\
\hline $\begin{array}{l}\text { College } \\
\text { B }\end{array}$ & Actual value & 0.738 & 0.746 & 0.718 & & & & & & \\
\cline { 2 - 11 } & Predicted value & 0.759 & 0.778 & 0.795 & 0.805 & 0.843 & 0.827 & 0.0168 & 0.2628 & 1 \\
\hline $\begin{array}{l}\text { College } \\
\text { C }\end{array}$ & Actual value & 0.672 & 0.728 & 0.758 & & & & & & \\
\cline { 2 - 11 } & Predicted value & 0.735 & 0.748 & 0.769 & 0.784 & 0.794 & 0.812 & 0.0162 & 0.2642 & 0.9879 \\
\hline $\begin{array}{l}\text { College } \\
\text { D }\end{array}$ & Actual value & 0.681 & 0.694 & 0.726 & & & & & & \\
\cline { 2 - 10 } & Predicted value & 0.725 & 0.736 & 0.751 & 0.759 & 0.774 & 0.781 & 0.0361 & 0.3957 & 0.8915 \\
\hline
\end{tabular}


Paper-A Collaborative Education Mechanism for College Students' Physical and Mental Health..

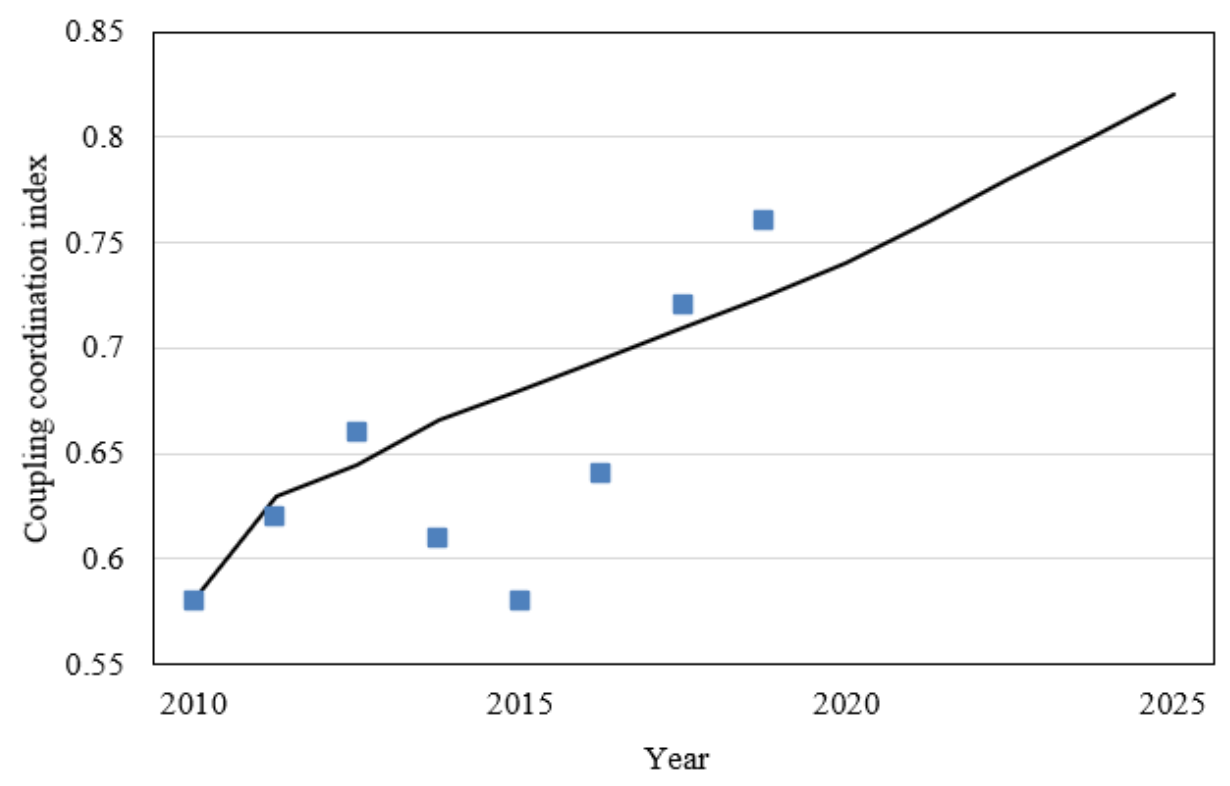

(A)

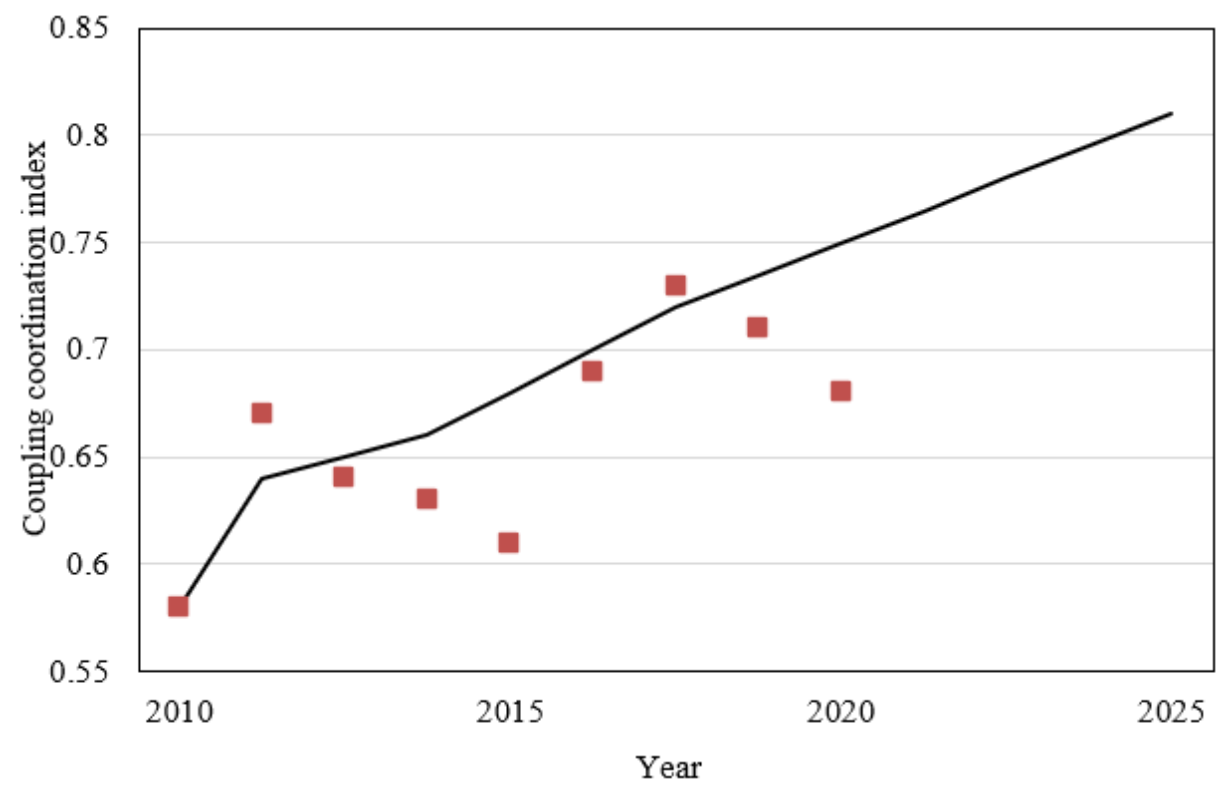

(B) 
Paper-A Collaborative Education Mechanism for College Students' Physical and Mental Health...

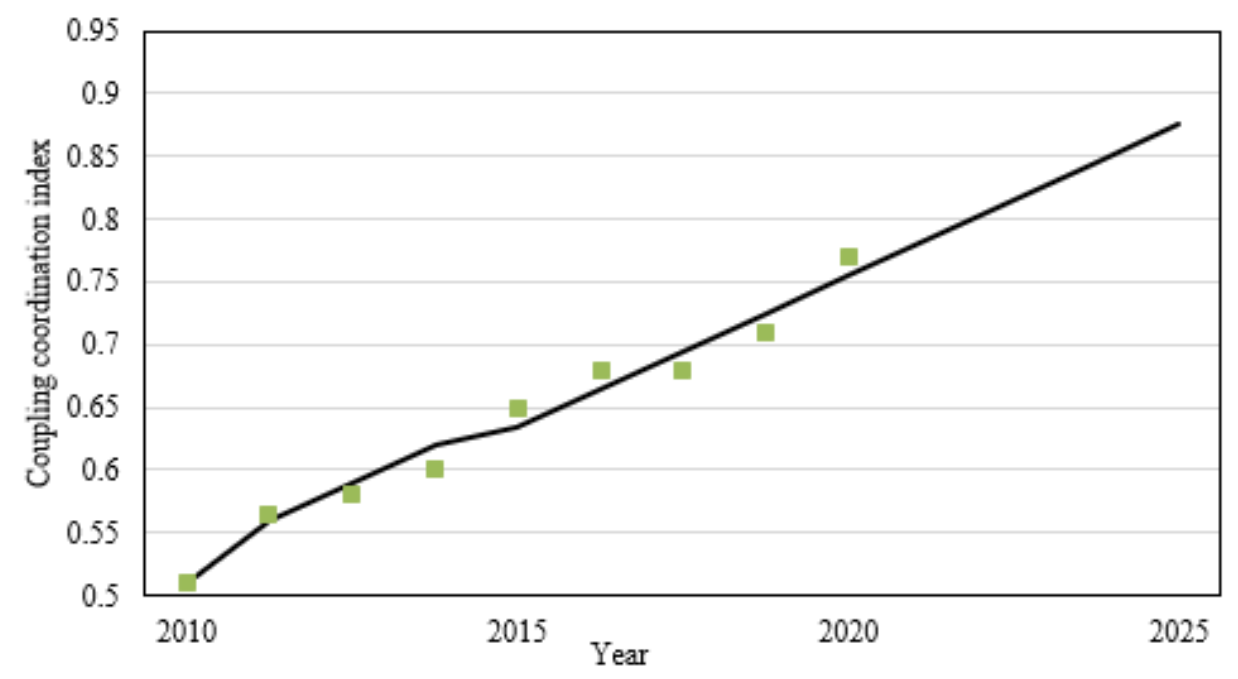

(C)

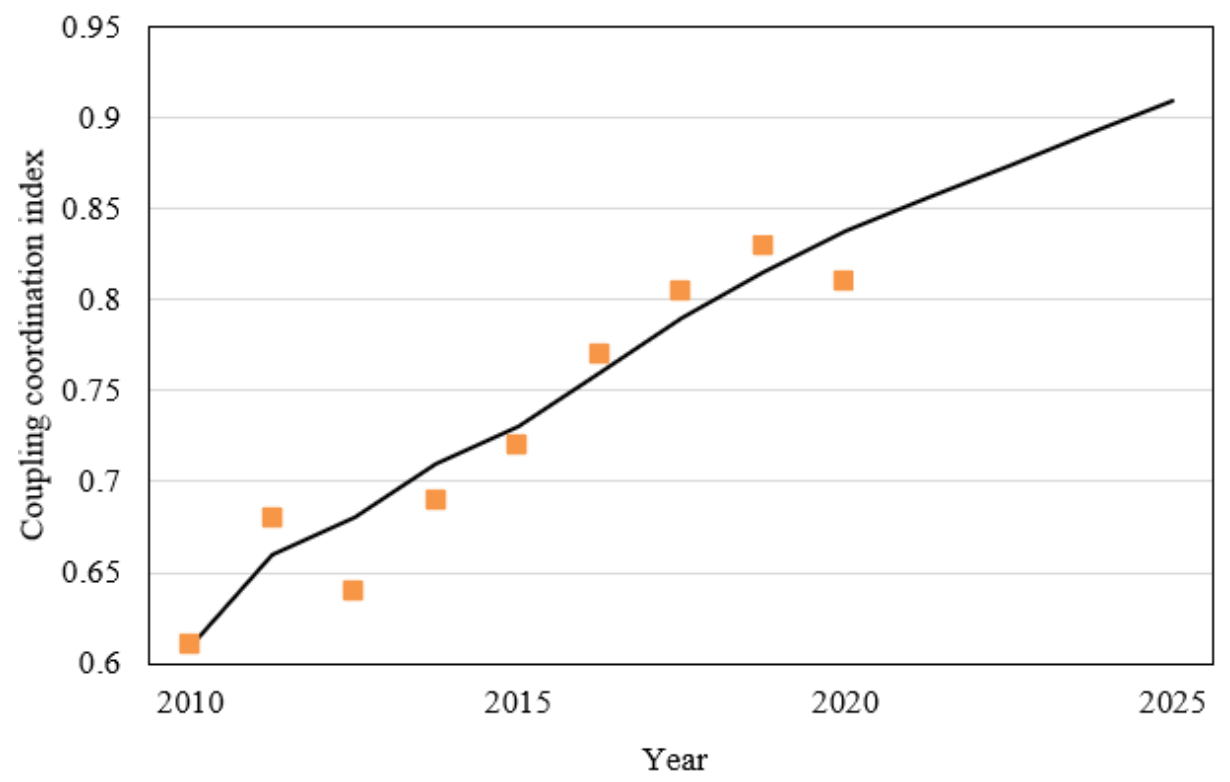

(D)

Fig. 3. Fitting diagrams of actual and predicated values of coupling coordination of collaborative education from 2010 to 2025

According to Figure 3, under current development trend, the degree of coupling coordination between the two education systems in the 4 colleges has been significantly improved compared with 2020, and the effect of collaborative education will be improved further. Within a certain time period in the future, the degree of coupling 
coordination between the two education systems in College A and College B will be stable at a high-level moderately coordinated stage. As for College B and College D, they will enter a stage of highly coordinated. The coupling coordination degree of the two education systems is expected to exceed 0.85 from 2020 to 2025 . Therefore, the current collaborative education mechanism of physical and mental health education and safety education implemented by these 4 colleges is relatively reasonable.

\section{Conclusion}

To cope with the shortage in research on the collaborative education mechanism for college students' physical and mental health education and safety education under complex background, this paper explored the said matter to fill in this research gap. At first, this paper constructed the content system for the two education systems, established the coordination evaluation model and applied the grey prediction model to the prediction and analysis of the development status of college students' physical and mental health education and safety education, thereby giving reasonable judgement on the development trend of collaborative education. Then, this paper gave the calculation results of the evaluation indexes of a few studied colleges from 2008 to 2019, and drew the conclusion that the evaluation indexes of these colleges showed an upward trend year by year after the implementation of the collaborative education mechanism. At last, this paper also obtained the actual and predicted situations of the coupling coordination of collaborative education in these colleges from 2018 to 2023, and verified that the current collaborative education mechanism adopted in these 4 colleges is relatively reasonable.

\section{$7 \quad$ References}

[1] Li, G. (2021). The relationship between the degree of interest in physical education and the mental health of college students. ACM International Conference Proceeding Series, 846849. https://doi.org/10.1145/3452446.3452648

[2] Li, X., Shi, X. (2021). Design and application of mental health intelligent analysis system for college students majoring in physical education. In Journal of Physics: Conference Series, 1852(3): 032049. https://doi.org/10.1088/1742-6596/1852/3/032049

[3] Wang, M., Song, Y., Qin, H. (2017). Experimental study on the influence of exercise intervention on the physical and mental health of contemporary college students. Boletin Tecnico/Technical Bulletin, 55(15): 456-461.

[4] Cao, W. (2015). Influence of moderate movement and training on the physical and mental health of college students. ISME 2015 - Proceedings of the Information Science and Management Engineering III, 224-227.

[5] Xu, L., Zhang, W., Han, J.J. (2011). Study on the effects of yoga on female college students' physical and mental health. In Advanced Materials Research, 187: 164-168. https://doi.org/10.4028/www.scientific.net/AMR.187.164

[6] Zhang, J. (2021). Research on psychological crisis intervention mechanism of higher vocational college students based on psychological data mining. In 2021 4th International 
Paper-A Collaborative Education Mechanism for College Students' Physical and Mental Health...

Conference on Information Systems and Computer Aided Education, 2353-2356. https://do i.org/10.1145/3482632.3487428

[7] Gong, K.X. (2020). Extensible Strategies and Their Performance for Mental Health Education in Colleges, International Journal of Emerging Technologies in Learning, 15(9): 205218. https://doi.org/10.3991/ijet.v15i09.14037

[8] Yang, Z. (2019). Psychological health course teaching mode based on students' high-order thinking ability development. International Journal of Emerging Technologies in Learning, 14(4): 101-112. https://doi.org/10.3991/ijet.v14i04.10111

[9] Prat, F., Gras, M.E., Planes, M., González-Iglesias, B., Sullman, M.J.M. (2015). Psychological predictors of texting while driving among university students. Transportation Research Part F: Traffic Psychology and Behaviour, 34: 76-85. https://doi. org/10.1016/j.trf.2015.07.023

[10] Long, Z., Zhang, J. (2015). Research on the psychological problems of private higher vocational students by using network and mobile terminal. Metallurgical \& Mining Industry, (9): 579-586.

[11] $\mathrm{Su}$, G.Q. (2015). Research on the effectiveness of nutrition and food safety education of the Taekwondo college students in China based on local fractional algorithm. The Open Cybernetics \& Systemics Journal, 9(1): 1979-1984. https://doi.org/10.2174/1874110X0150 9011979

[12] Li, L., Zhang, K., Li, T. (2020). A Performance Analysis Model for the Training and Education of Information Security Talents, International Journal of Emerging Technologies in Learning, 15(5): 140-155. https://doi.org/10.3991/ijet.v15i05.13329

[13] Cheng, Y. (2017). Research on public safety education of Chinese college students in network multimedia environment. AGRO Food Industry Hi-Tech, 28(3): 3353-3355.

[14] Chen, H. (2017). Research on the construction of safety education system for college students. AGRO Food Industry Hi-Tech, 28(1): 1240-1244.

[15] Xu, Y.F., Shi, L.S. (2020). Research and design of APP for primary school students' safety education based on embodied cognitive theory. In 2020 IEEE 2nd International Conference on Computer Science and Educational Informatization (CSEI), 1-4. https://doi. org/10.1109/CSEI50228.2020.9142491

[16] Bejan, A., Xi, M., Parker, D.L. (2020). Outcomes of a safety and health educational intervention in auto body and machine tool technologies vocational college programs: The technical education curricula for health and safety (TECHS) study. Annals of work exposures and health, 64(2): 185-201. https://doi.org/10.1093/annweh/wxz092

[17] Åsgård, T. (2018). Health, safety and environment in the teaching of project management. The case of bachelor education in construction engineering in Norway. Procedia computer science, 138: 688-696. https://doi.org/10.1016/j.procs.2018.10.091

[18] Miao, N., Gao, S., Lin, X., Wang, H. (2021). Research on the future health of society based on college students' physical health standards. In 2021 International Conference on Information Technology and Contemporary Sports (TCS), 477-480. https://doi.org/10.110 9/TCS52929.2021.00102

[19] Huang, R.F., Gao, C.M. (2021). Development of psychological health education modes for college students based on information technology. In 2021 2nd International Conference on Education, Knowledge and Information Management (ICEKIM), 888-891. https://doi.o rg/10.1109/ICEKIM52309.2021.00201

[20] Yang, A. (2020). Study on safety education for college students based on risk society theory. In 2020 International Conference on Urban Engineering and Management Science (ICUEMS), 647-650. https://doi.org/10.1109/ICUEMS50872.2020.00142 


\section{Authors}

Xiaoning Song, female, born in September 1982, Hui nationality, from Handan, Hebei Province, associate professor of Tangshan polytechnic college, with a doctor's degree of education, majors in Ideological and political education and mental health education. National second-class psychological counselor and model of teacher ethics in Hebei Province. Participated in the writing of many planning textbooks, such as guidance for mental health of college students, course of Ideological and political theory of college students, career development and employment guidance, etc. Participate in relevant research. The first prize of teaching achievement in Hebei Province and the first prize of teaching ability competition in Higher Vocational Colleges in Hebei Province.

Nailei Lin, male, born in November 1982, Han nationality, from Liaocheng, Shandong Province, associate professor of Tangshan polytechnic college, with a Master's degree of education, research direction: Ideological and political education and mental health education (email: lnlnoah@126.com).

Article submitted 2021-12-05. Resubmitted 2022-01-12. Final acceptance 2022-01-13. Final version published as submitted by the authors. 